\title{
CONTRACEPTIVE PREVALENCE RATE, UNMET NEED FOR FAMILY PLANNING AND ITS ASSOCIATED FACTORS AMONG WOMEN OF REPRODUCTIVE AGE GROUP
}

\author{
Khola Noreen ${ }^{1}$, Kausar Aftab Khan ${ }^{2}$, Naeem Khan ${ }^{3}$, Shahzad Ali Khan ${ }^{4}$, Nadia Khalid ${ }^{5}$
}

\author{
${ }^{1}$ Assistant Professor, Department of Community Health Sciences, Gujranwala Medical College, Gujranwala, \\ Pakistan \\ ${ }^{2}$ Assistant Professor, Department of Community Health Sciences, Gujranwala Medical College Gujranwala, \\ Pakistan \\ ${ }^{3}$ Associate Professor, Department of Community Health Sciences, Gujranwala Medical College Gujranwala, \\ Pakistan \\ ${ }^{4}$ Associate Professor Health Services Academy Islamabad \\ ${ }^{5}$ Senior Lecturer, Department of Community Health Sciences. Bahria University Medical \& Dental College, Karachi, \\ Pakistan \\ Correspondence: Khola Noreen, Email:_dr_khaula@yahoo.com
}

\begin{abstract}
Background: Family planning includes knowledge, services, attitude, policies and practices which enable individuals to decide whether they want to have child and allow them to avoid unwanted pregnancy. Pakistan with population of 195.390 million with estimated population growth rate as 1.89 is the sixth most populous country in the world. Our objectives were to assess the total demand of family planning, contraceptive prevalence rate, unmet need for family planning and factors associated with unmet need of family planning among women of reproductive age group.

Methods: We conducted this cross-sectional study on 355 females of reproductive age attending the out-patient department as patient or attendant. Data were collected using structured questionnaire after the participants' verbal consent.

Results: The prevalence of unmet need was $34 \%$. The proportion of unmet need for spacing was $63.6 \%$ and for limiters it was found to be $36.3 \%$. Contraceptive prevalence rate was $57 \%$. Total demand for family planning was $92.1 \%$.Almost all study participant had knowledge regarding at least one method of contraception. Unmet need of family planning was found to be significantly associated with age and education status of women. High unmet need was there in women with low education status $(p=0.047)$ and older age group $(p=0.003)$. Main reasons for not using contraceptive was family opposition both family and husband (66.9), and fear of side effects $(17.3 \%)$.

Conclusion: More than one third females had unmet need which strongly points towards the strong influence of various socio demographic factors contributing towards the unmet need.
\end{abstract}

Keywords: Unmet need, contraceptive prevalence rate, total demand of family planning

\section{Introduction}

Family planning includes knowledge, services, attitude, policies and practices which enable individuals to decide whether they want to have child and allow them to avoid unwanted pregnancy. It is basic right of every individual to have access to family planning services and to decide about family size (1). Family planning can improve maternal and child health indicators and can reduce maternal deaths by maintaining health spacing (2).

Pakistan with population of 195.390 million with estimated population growth rate as 1.89 is the sixth most populous country in the world. Pakistan has poor demographic and family planning indicators as compare to our countries of region with highest child mortality rate of 81.1 and infant mortality rate of 65.8 per 1000 live births. In order to improve current statistics there is dire need to improve family planning services (3).

Pakistan has made commitment during International Conference on Population and Development and signatory to The London Summit on family planning 2012. This meeting has inspired the Family planning 2020 agenda which aims to provide family planning services to additional 120 million women in 69 countries of world with gross national income less than $\$ 2500$ (4). According to FP 2020 commitment Pakistan need to increase contraceptive prevalence rate (CPR) to $50 \%$ while CPR during 2016 is reported to be $35.5 \%$ (5).

Family planning can pave the way to successful 
achievement of Sustainable Development Goals (SDGs). The impact of family planning in achievement of SDGs is well depicted from Statement of Global Health: Science and Practice as Investing in Family Planning: Key to achieving to Sustainable Development Goals",. Family planning can be effective strategy that can improve the progress towards five themes of SDGs namely Peace, prosperity, people, partnership and planet (6).

The success of achieving the targets of millennium development goals, sustainable developmental goal and FP 2020 can be measured by Contraceptive prevalence rates and unmet of family planning (7). These two indicators are useful in mapping the success of universal access of reproductive health services in country. Sum of unmet needs and contraceptive prevalence rates points towards total demand of family planning (7).

Unmet need of family planning refers to women who are sexually active or fecund and don't want next pregnancy (Limit) or want to delay it (space) for at least two years but currently not using any contraceptive method. It indicates gap between fertility preferences and actual practices $(8,9)$.

According to report of Pakistan Demographic and Health 2012-13 survey total $20 \%$ women has unmet need of planning, $9 \%$ for spacing and $11.5 \%$ for limiting. Unmet need is high in rural area (22\%) as compared to $17 \%$ in urban area. Province wise data suggest that highest unmet need is Baluchistan (31\%) and lowest in Islamabad (13\%). It is highest in uneducated women $(22 \%)$ and lowest in women with more than secondary education $(15 \%)(10)$.

According to Contraceptive performance report of Pakistan Bureau of Statistics 2015-16 over all contraceptive prevalence rates is reported $35.5 \%$. Its highest in Punjab (38.9\%) and lowest in Baluchistan $(13.8 \%)$ while in Sindh it is $25 \%$ and $46 \%$ in Khyber Pakhtunkhwa. When compared to year 2014-15, over all contraceptive prevalence rate has been increased by 8.6\% during year 2015-16 (5).

Currently Government of Pakistan is main service provider for family planning $(47 \%)$ while contribution of private sector is almost half (23\%) (11). In spite of efforts of government of Pakistan we still not able to achieve the expected bench mark. .Current situation could be really alarming for our country where approximately $61 \%$ population is living below US $\$ 2$ a day (12).

Aim of our study was to find current contraceptive prevalence, unmet need of family planning, total demand of fertility and the factors associated with unmet of family planning. The most pressing issue is unmet need of family planning. Pakistan has strong family planning program yet there is considerable un met need .Estimates of un met need and contraceptive prevalence rate is vital index for monitoring the success of family planning program. Identifying the factors associated with unmet need of family planning can help the planners and decision makers to overcome the gap between contraceptive preferences and actual practices. This would definitely help in improving maternal and child health indicators and reducing the burden on health care system.

\section{Methodology}

This cross sectional study was conducted at Union council of Basic Health Care Unit (BHU) Kot Hara. Data was collected from females attending the OPD as patient or attendant. Data was collected from June to December 2017. Inclusion criteria include all married females of reproductive age group (15-49 years) who are sexually active and fecund, willing to participate in study. Exclusion criteria includes unmarried females , not living with husbands, having reproductive health issue, infertile, women with menopause, those who have under gone hysterectomy, or early menopause.

Sample size was calculated using WHO calculator, in which prevalence is taken as $35.5 \%$ (10), margin of error as $5 \%$ and confidence interval $95 \%$. On the basis of this sample size was calculated to be 349 which was inflated to 355 . Study participants were enrolled by non probability convenient sampling.

Data was obtained by using structured questionnaire prepared by literature search and reviewing the questionnaires of Pakistan Demographic Health Survey. Data was collected by (lady health visitors) LHW's of union council. Questionnaire consists of two parts. First part was socio demographic variables and second part includes the variables related to reproductive history of participants. Data was taken from participants in local language by LHW's .Duration of each session was about 30-40 minutes. Ethical approval was obtained. Anonymity and confidentiality was maintained during data collection. Verbal consent was obtained from participants .Data was analyzed by using SPSS version 23. Descriptive statistics were calculated for continuous data as Mean and standard deviation. Chi square test was applied to find the association of socio demographic variables with met and un met needs of family planning. $p$ value less than 0.05 was taken as significant.

\section{Results}

The ages of study participants ranged between 18-49 years (women of reproductive age ). Mean age recorded was 25.9+7.8. Maxium number of study participants were in between 25-34 years. Mean number of children per women in our study was 4.1. Maximum proportion of women had completed their education till primary level. More than half of participant were living in joint family system. Majority of the women were unemployed $(77.7 \%)$.Details of socio demographic data is given in Table 1. 
Table 1: Socio demographic Characteristics of study participants

\begin{tabular}{|l|l|l|}
\hline Variable & Frequency & Percentage \% \\
\hline Age of Women (years) & & \\
\hline $15-19$ & 13 & 3.6 \\
\hline $20-24$ & 65 & 18.3 \\
\hline $25-29$ & 138 & 38.8 \\
\hline $30-34$ & 91 & 25.6 \\
\hline $35-39$ & 21 & 5.9 \\
\hline $40-44$ & 16 & 4.5 \\
\hline $45-49$ & 11 & 3.0 \\
\hline Education Status & & \\
\hline Un Educated & 61 & 17.1 \\
\hline Primary & 73 & 20.5 \\
\hline Middle & 93 & 26.1 \\
\hline Matric & 44 & 18.0 \\
\hline Intermediate & 66 & 12.9 \\
\hline Graduation & 11 & 3.1 \\
\hline Masters & 5 & 1.4 \\
\hline Post Graduation & 2 & 0.5 \\
\hline Family Structure & & \\
\hline Nuclear & 167 & 47.0 \\
\hline Joint & 188 & 52.9 \\
\hline Occupation & & \\
\hline Un employed & 210 & 59.1 \\
\hline Working & 145 & 40.8 \\
\hline Monthly family income & & \\
\hline$\leq 25,000$ & 108 & 30.4 \\
\hline $25,000-50,000$ & 121 & 34 \\
\hline$>50,000$ & 126 & 35.4 \\
\hline & & \\
\hline
\end{tabular}

Out of 355 study participants 202(57\%) were currently using contraception. Since the data was collected from Union council of Basic Health Unit almost all the study participants had heard about at least one method of contraception. Most commonly used contraceptive was intrauterine contraceptive devices. Contraceptive prevalence rate was $57 \%$ and total un met need was $34 \%$ excluding those who are currently pregnant, want conception and those who are in post partum period. Details are shown in Table 2.

\section{Table 2: Current contraceptive practice}

\begin{tabular}{|c|c|c|}
\hline Variable & Frequency & Percentage \\
\hline $\begin{array}{l}\text { Have you heard about any contraception } \\
\text { Yes } \\
\text { No }\end{array}$ & $\begin{array}{c}352 \\
3 \\
\end{array}$ & $\begin{array}{c}99.1 \\
1.1 \\
\end{array}$ \\
\hline $\begin{array}{l}\text { Females currently practicing contraception } \\
\text { Yes } \\
\text { No }\end{array}$ & $\begin{array}{l}202 \\
153\end{array}$ & $\begin{array}{c}56.9=57 \\
43\end{array}$ \\
\hline $\begin{array}{l}\text { Types of contraceptives among females } \\
\text { current } \\
\text { family planning users }\end{array}$ & \multicolumn{2}{|c|}{$n=202(57 \%)$} \\
\hline $\begin{array}{l}\text { MODERN METHODS } \\
\text { Oral pills } \\
\text { Intrauterine contraceptive devices } \\
\text { Barrier method } \\
\text { Injectables } \\
\text { Tubal ligation }\end{array}$ & $\begin{array}{l}16 \\
65 \\
32 \\
15 \\
13\end{array}$ & $\begin{array}{c}7.9 \\
32.1 \\
15.8 \\
7.4 \\
6.4 \\
\end{array}$ \\
\hline Total Modern Method & 141 & 69.8 \\
\hline $\begin{array}{l}\text { TRADITIONAL METHODS } \\
\text { Safe period } \\
\text { Withdrawal } \\
\text { Lactation }\end{array}$ & $\begin{array}{l}27 \\
21 \\
13\end{array}$ & $\begin{array}{c}13.3 \\
10.3 \\
6.4 \\
\end{array}$ \\
\hline $\begin{array}{l}\text { Total(Modern + Traditional) } \\
\text { Contraceptive prevalence rate }\end{array}$ & $141+61=202$ & 57 \\
\hline $\begin{array}{l}\text { Not using contraception } \\
\text { Currently pregnant } \\
\text { Desiring next pregnancy } \\
\text { In post partum period }\end{array}$ & $\begin{array}{c}153 \\
3 \\
17 \\
12\end{array}$ & $\begin{array}{c}43 \\
\\
1.96 \\
11.1 \\
7.8\end{array}$ \\
\hline Total un met need for family planning & $153-32=121$ & 34 \\
\hline
\end{tabular}

On inquiring the reason for not using any family planning method most common reason given by participants was family opposition (both mother in law and husband) after that there was fear of side effects $(17.3 \%)$ including weight gain, excessive bleeding. Other issues include poor availability and administrative issues. Details of reasons for not using contraceptives are given in table 3 . Table 3: Reason for not using any contraceptive method $(n=121)$

\begin{tabular}{|l|l|l|}
\hline Variable & Frequency & Percentage \\
\hline $\begin{array}{l}\text { Fear of side effects (excessive } \\
\text { bleeding, weight gain }\end{array}$ & 21 & 17.3 \\
\hline $\begin{array}{l}\text { False beliefs (permanent } \\
\text { infertility, false religious beliefs ) }\end{array}$ & 12 & 9.9 \\
\hline Husband opposition & 42 & 34.7 \\
\hline $\begin{array}{c}\text { Mother in law opposition } \\
\begin{array}{c}\text { Poor availability, lack of } \\
\text { accessibility (long distance) }\end{array}\end{array}$ & 39 & 32.2 \\
\hline $\begin{array}{c}\text { Administrative issues } \\
\text { previous bad experience } \\
\text { with the facility }\end{array}$ & 2 & 1.6 \\
$\begin{array}{c}* \\
\text { attitude of service provider }\end{array}$ & 3 & 1.6 \\
\hline
\end{tabular}

Table 4 shows the association of socio economic condition with met and unmet need of family planning. Age and education status of women is found to be significantly associated with unmet need of family planning.

Table 4: Association of socio demographic variables with met and unmet need of family planning

\begin{tabular}{|c|c|c|c|}
\hline Variables & $\begin{array}{l}\text { Met need } \\
(n=202)\end{array}$ & $\begin{array}{l}\text { Un met need } \\
(n=131)\end{array}$ & $P$ value \\
\hline Variables & \multirow[t]{2}{*}{$\mathbf{n}$} & \multirow[t]{2}{*}{$\%$} & \\
\hline Age(years) & & & \\
\hline$\leq 29(n=194)$ & $113(55.9)$ & $81(61.8)$ & \multirow{3}{*}{0.047} \\
\hline $30-39(n=112)$ & $82(40.5)$ & $30(22.9)$ & \\
\hline$\geq 40(n=27)$ & $7(3.4)$ & $20(15.2)$ & \\
\hline \multicolumn{4}{|l|}{ Education Status } \\
\hline Primary \& below $(n=134)$ & $52(25.7)$ & $82(62.5)$ & \multirow{4}{*}{0.003} \\
\hline $\begin{array}{l}\text { Secondary \& Matric } \\
(\mathrm{n}=115)\end{array}$ & $91(45)$ & $24(18.3)$ & \\
\hline $\begin{array}{l}\text { Intermediate \&Graduation } \\
(\mathrm{n}=77)\end{array}$ & $52(25.6)$ & $25(19)$ & \\
\hline $\begin{array}{l}\text { Masters \&Post graduation } \\
(\mathrm{n}=7)\end{array}$ & $7(3.4)$ & - & \\
\hline \multicolumn{3}{|l|}{ Family structure } & \multirow{4}{*}{0.214} \\
\hline Nuclear (157) & $91(45)$ & $66(50)$ & \\
\hline Joint(176) & $111(54.9)$ & $65(49.6)$ & \\
\hline \multicolumn{3}{|l|}{ Occupation } & \\
\hline Working $(\mathrm{n}=141)$ & $81(40)$ & $60(45.8)$ & \multirow{2}{*}{1.547} \\
\hline Un employed (192) & $121(59.9)$ & $71(54.1)$ & \\
\hline \multicolumn{3}{|l|}{ Monthly family income } & \multirow{4}{*}{1.907} \\
\hline$\leq 20,000(112)$ & $67(33.1)$ & $45(34.3)$ & \\
\hline $20,000-50,000(105)$ & $70(34.6)$ & $35(26.7)$ & \\
\hline$\geq 50,000(116)$ & $65(32.1)$ & $51(38.9)$ & \\
\hline
\end{tabular}


Figure 1 shows the details of current contraceptive prevalence, met, un met need and total demand of family planning

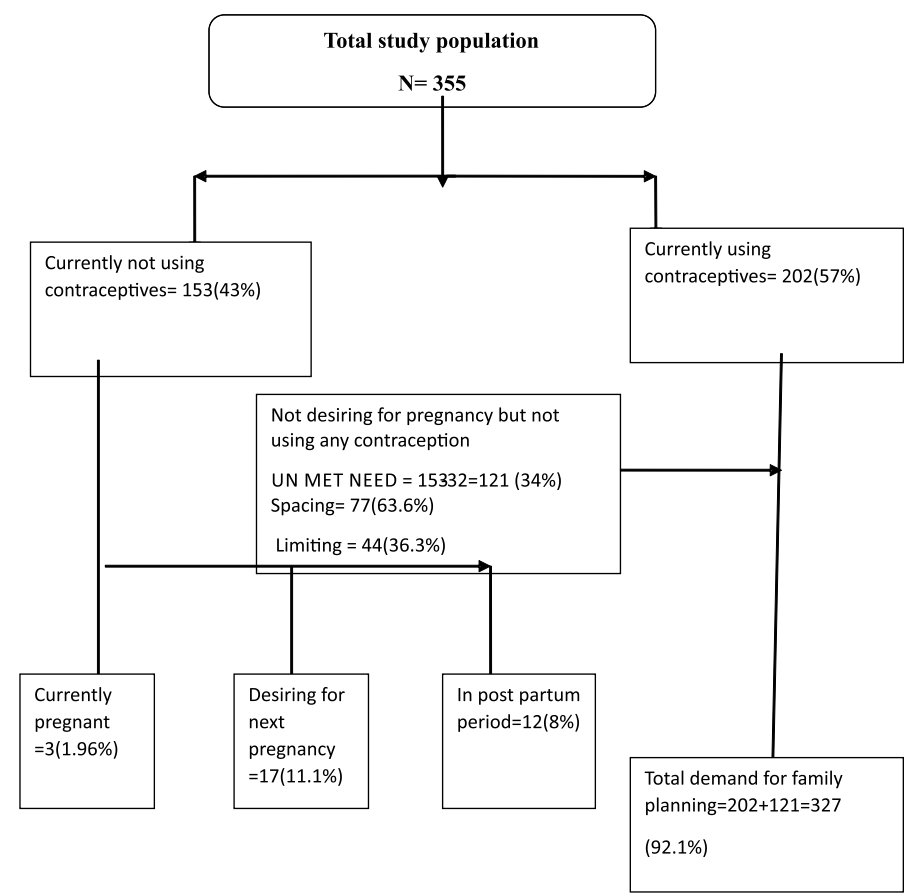

Figure 1: Flow chart showing met, unmet and total demand of family planning

\section{Discussion}

This study was conducted on the females attending Basic Health Care Unit where family planning services are available. Participants had knowledge and accessibility to contraceptives, yet the results suggest the considerable unmet need which strongly points towards the strong influence of various socio demographic factors contributing towards the unmet need.

In our study contraceptive prevalence rate (CPR) was found to be $57 \%$. Another study conducted in Bangladesh reported the contraceptive prevalence rate as $61 \%$ (13). In our study mostly participants were using modern methods (69.8\%) According to contraceptive performance report 2015-16, CPR in Pakistan based on modern method was $35.5 \%$ (5).

CPR is vital indicator used by Government and all stake holders to assess the progress towards Millennium Development goals, Sustainable development goals and Family planning vision 2020 hence varies considerably in different countries according to success of health policies (14). In our study data was collected from female patients attending Basic Health Care Unit where family planning services are available that might be the reason for comparatively better figures. It is interesting to note that CPR in our study is $57 \%$ which is almost equal to desired CPR as per Family planning vision 2020 (4) .

Mean number of children per women in our study was
4.1. Pakistan Demographic Health Survey 2012-13 (PDHS) reported the total fertility rate (TFR) as 3.1 which mean that every Pakistani women on average give birth to 3.1 children during her reproductive years (10). According to this survey TFR in urban area is 3.2 while in rural areas it was $4.2(10)$ which is comparable to our study and far beyond the targeted replacement level fertility of 2.1 as per millennium development goal. In recent study conducted in Lahore around $65 \%$ female desire for more than two children (15). Study conducted by Mustafa etal reported that desire for average number of children per family was four with preference of male child (16).

On inquiring about knowledge of contraception almost all the participants had heard about at least one method of contraception. This finding is interesting to note that in our study lady health visitors were the main source of information in locality. Previous evidence has also supported the effective role of LHV's on acceptors. They have strong influence on decision making. It is worthwhile to effectively utilize their services as advocates and promoters of family planning program $(17,18)$.

Study conducted on women of rural Sindh reported that $80 \%$ of women have ever heard about at least one method of contraception and $26 \%$ of females were actually practicing contraception (18). Study conducted by Mansoor ul Hassan is in accordance with our study in which nearly all participants had knowledge regarding contraception (19). Similarly study conducted by Mustafa et all also reported that maximum number of participant had knowledge about at least one method of contraception (16). These finding are also concurrent with results of PDHS2012-13(10).

In our study most common method of contraception was intrauterine contraceptive devices which are concurrent with findings of present national data (20). However these findings are in contrast with PDHS which report condoms as most widely practice contraceptives (10) .Study conducted by Mustafa et all also reported the condoms being most prevalent method of contraception (16) .Study conducted by Mehwish etal is also in accordance with our study in which most common contraceptive used was intra uterine contraceptive devices (18). Study conducted in Peshawar reported injectable as most common method of contraception (21).

Various socio cultural factors like in laws opposition /husband opposition is also strong contributory factor un met need similar trend is also observed in previous research $(10,16)$. IMPACT Survey conducted to analyze the factors limiting the effectiveness of family planning program highlighted that women intention to use family planning increase by $31 \%$ if husband approved to family planning (22). Previous studies have also documented the influence of husband and mother in laws in decision making regarding contraception $(23,24)$. Study conducted on Punjabi women reported that women had 
perception that with the use of contraceptives they would have conflict with their husband's attitude towards fertility and it is not accepted socially and culturally (25). Since in our study mostly women were have access to family planning services and almost all of them have heard about at least one method but still there is considerable unmet need. Husband and mother in law opposition may be strong contributory factors. Previous evidence has also supported that fact that if man has strong sense of responsibility and has perception that family planning can improve the women health and vital for economic stability of family, they are more likely intended to use the modern contraceptives (26). Such strategies must be adapted in rural areas where there is still trend of preferring traditional methods as compared to modern contraceptives (27) .Literature has supported the fact that females are more reliant on husband to make decision regarding family planning. This is complex issue and need to be addressed even protocol for female sterilization in our country requires the explicit permission from their husband (27).

Fear of side effects and false beliefs were also documented in $17.3 \%$ of participants in our study. Similar results are also reported from previous studies $(28,29)$. Similarly religious factors are also reported to be strong contributory factor for unmet need of family planning. Studies have reported that participants are in opinion that fertility is decided as per God's will $(30,31)$.

The results of our study indicated that contraceptive use decreases with age. This shows that as fertility decrease with progression in age trend of contraceptive usages also declines. Consistent increase in contraceptive usages in age between 20 -34 years indicates that women of reproductive age group are more concern to use contraceptives. This type of relationship between age and contraceptive use has been observed in previous studies $(32,33)$. The reason documented was that with advancing age rate of unintended pregnancies also decreases and another reason of decline is fear adverse health outcomes (34).

On finding the association of socio demographic variables with met and un met need of family planning .It was found that un met needs are higher in women with level of education till primary and below and women with better education status are more likely to use contraceptives. Reason being that better education provides more information and also improves accessibility to family planning services. Moreover previous evidence has also proved that women with better education status are more professionally engaged and trend of contraceptive usage is more as they want to limit family size because of their professional commitments (35).

There is an association between high level of education and small family size .Women education can reduce fertility rate by $0.3-0.5$ children per women (36). Pakistan has low adult literacy rate .overall literacy rate reported by world data report is $56 \%$. This is even low in rural area which makes the scenario even more worse (37).

The study identified the strong need of improving women education status and empower the women which can definitely influence the decision making. Better education can alleviate the women confidence and promote mutual decision making which can reduce the family pressure and opposition. Existing family planning program should be improved. Services of Lady Health Visitors should be effectively utilize as advocates and promoters of family planning program. Well targeted behavior change programs involving husband can change the attitudes and encourage them to adopt family planning. Moreover, family planning programs should focus on addressing the apprehensions and fears related to side effects .It can be done by implementing comprehensive health education and counseling sessions

Limitation of study was that data was only collected from females. So study only focuses on barriers perceived by females on contraceptive practices. More over data was collected from basic health unit where family planning services were available so this fact limits the generalizibility of findings to rest of population which do not have easy accessibility to contraceptive. Since it was cross sectional survey so causal relationship was difficult to establish causal association.

\section{References}

1 Letamo G, NavaneethamK. Levels, trends and reasons for unmet need for family planning among married women in Botswana: a crosssectional study. BMJ open. 2015 Mar 1; 5(3):e00660

2 Genet E, Abeje G, Ejigu T. Determinants of unmet need for family planning among currently married women in Dangila town administration, Awi Zone, Amhara regional state; a cross sectional study. Reproductive health. 2015 May 13; 12(1):42

3 Economic Survey Government of Pakistan, 2016-2017. [Internet]. [Cited 2014 Sep3].Available from:http;//www.cidapsu.org.pk

4 Modern contraceptive use, unmet need, and demand satisfied among women of reproductive age who are married or in a union in the focus countries of the Family Planning 2020 initiative: a systematic analysis using the Family Planning Estimation Tool Cahill, Niamh et al.The Lancet, Volume 391 , Issue 10123, 870 - 882

5 Contraceptive Performance Report 20152016.Islamabad (PK): Pakistan Bureau of Statistics Government of Pakistan; April2017.12. Report NO.:6.[cited2017Sept12] Available fromhttp://www.pbs.gov.pk/sites/ default/files//social_statistics/contraceptive_per formance_repot

$6 \quad$ Glob Health Sci. Pract Advance Access Article published on June 9, 2016 as doi: 10.9745/GHSP-D-15-00374 
K han S, Zareen $H$, Shahzad S.Factors and Determinants of Unmet Needs: Identifying Association Between Variables and Unmet Needs Among Married Women of Child Bearing Age in Lahore, Pakistan. Int Arch BioMed ClinRes. 2018;4(1):165-169

8 Darroch JE, Singh S. Trends in contraceptive need and use in developing countries in 2003, 2008, and 2012: an analysis of national surveys. Lancet. 2013. doi:10.1016/S01406736(13)60597-8

9 United Nations, Department of Economic and Social Affairs, Population Division (2014).World Contraceptive Use 2014 (POP/DB/CP/Rev201

10 Pakistan Demographic and Health Survey Key Findings (PDHS), 2012-13. Islamabad (PK): National Institute of Population studies;2013.56,16 . Available from http://www.nips.org.pk/ abstract_files/PDHS\%20Key\%20Findings $\% 20$ FINAL\%201.24.14.pd

11 National Institute of Population Studies (NIPS) and ICF International, Pakistan Demographic and Health Survey 2012-13, National Institute of Population Studies (NIPS), Islamabad, Pakistan; ICF International, Calverton, Md, USA, 2013

12 Population Reference Bureau, "World Population Data Sheet," 2013 http://www.prb .org/Publications/Datasheets/2012/worldpopula tion-data-sheet.aspx

13 Islam, A. Z., Mondal, M. N. I., Khatun, M. L., Rahman, M. M., Islam, M. R., Mostofa, M. G., \& Hoque, M. N. (2016). Prevalence and Determinants of Contraceptive use among Employed and Unemployed Women in Bangladesh. International Journal of $\mathrm{MCH}$ and AIDS, 5(2), 92-102.

14 Cunningham, M., Bock, A., Brown, N., Sacher, S., Hatch, B., Inglis, A., \& Aronovich, D. (2015). Estimating Contraceptive Prevalence Using Logistics Data for Short-Acting Methods: Analysis Across 30 Countries. Global Health: Science and Practice, 3(3), 462-481. http://doi.org/10.9745/GHSP-D-15-0011

15 khan S, Zareen H, Shahzad S. Factors and Determinants of Unmet Needs: Identifying Association Between Variables and Unmet Needs Among Married Women of Child Bearing Age in Lahore, Pakistan. International Archives of BioMedical and Clinical Research [Internet]. 21Mar.2018 [cited 9May2018];4(1):165-9. Available from: https://iabcr.org/index.php/iabcr/ article/view/299

16 Ghulam Mustafa, Syed Khurram Azmat, Waqas Hameed, et al., "Family Planning Knowledge, Attitudes, and Practices among Married Men and Women in Rural Areas of Pakistan: Findings from a Qualitative Need Assessment Study,"
International Journal of Reproductive Medicine, vol. 2015, Article ID 190520, 8 pages, 2015. https://doi.org/10.1155/2015/190520.

17 Bhatti, Mansoor ul Hassan, and Sultan S. Hashmi 1993. Choice System of Contraceptive Methods and Drop-out in Family Planning. Islamabad: National Institute of Population Studies. (First Report)

18 Mubarik, M., Jameel, N., Kahlil, R. \& Gul, S. (2016). "Source of Knowledge and Choice of Contraceptive Method among Married Rural Women of Pakistan." International Journal of Recent Advances in Multidisciplinary Research, 3 (6), 1576-1580

19 Mansoor, B.H. 1995. Correlates of Choice of Contraceptive Methods in Pakistan, the Pakistan Development Review 34: 4 Part III (Winter 1995) pp. 889-898

20 National Institute of Population Studies (NIPS) and ICF International, Pakistan Demographic and Health Survey 2012-13, National Institute of Population Studies (NIPS), Islamabad, Pakistan; ICF International, Calverton, Md, USA, 2013.

21 Raheelah Amin, 2012. Choice of contraceptive method among females attending family planning center in Hayat Abad Medical Complex, Peshawar, J Pak Med Assoc, Vol. 62, No. 10, October 2012 International Journal of Recent Advances in Multidisciplinary Research1580

22 Family planning in Pakistan: an analysis of some factors constraining use.Sirageldin I, Norris D, Hardee JGStud Fam Plann. 1976 May; 7(5):144-54

23 Pasha O, Fikree FF, Vermund S. Determinants of unmet need for family planning in squatter settlements in Karachi, Pakistan. Asia-Pacific Population Journal. 2001;16(2):93-108.

24 Kadir MM, Fikree FF, Khan A, Sajan F. Do mothers-in-law matter? Family planning dynamics and fertility decision-making in urban squatter settlements of Karachi, Pakistan. Journal of Biosocial Science. 2003;35(4):545558. doi: $10.1017 /$ S0021932003005984

25 Obstacles to contraceptive use in Pakistan: a study in Punjab.Casterline JB, Sathar ZA, ul Haque M. Stud Fam Plann. 2001 Jun; 32(2):95110

26 Agha, S. (2010). Intentions to use contraceptives in Pakistan: implications for behavior change campaigns. BMC Public Health, 10, 450. http://doi.org/10.1186/14712458-10-450

27 Carton TW, Agha S. Changes in contraceptive use and the method mix in Pakistan: 1990-91 to 2006-28. Greenstar Research Department, Working Paper No. 3. Karachi, Pakistan: 
Greenstar Social Marketing. 2009

28 S. K. Azmat and G. Mustafa, "Barriers and perceptions regarding different contraceptives and family planning practices amongst men and women of reproductive age in rural Pakistan: a qualitative study," Pakistan Journal of Public Health, vol. 2, no. 1, pp. 17-23, 2012.

29 R. Neeti, D. K. Tanjea, K. Ravneet, and G. K. Ingle, "Factors affecting contraception among women in a minority community in Delhi: a qualitative study," Health and Population: Perspectives and Issues, vol. 33, pp. 10-15, 2014.

30 T. Tilahun, G. Coene, S. Luchters et al., "Family planning knowledge, attitude and practice among married couples in jimma zone, ethiopia," PLoS ONE, vol. 8, no. 4, Article ID e61335, 2013.

31 M. H. Bernhart and M. M. Uddin, "Islam and family planning acceptance in Bangladesh," Studies in Family Planning, vol. 21, no. 5, pp. 287-292, 1990.

32 Haq I, Sakib S, Talukder A. Sociodemographic Factors on Contraceptive Use among EverMarried Women of Reproductive Age: Evidence from Three Demographic and Health Surveys in Bangladesh. Medical Sciences. 2017;5(4):31. doi:10.3390/medsci5040031.

33 Factors influencing contraceptive use among women in Afghanistan: secondary analysis of Afghanistan Health Survey 2012. Osmani AK, Reyer JA, Osmani AR, Hamajima N Nagoya J Med Sci. 2015 Nov; 77(4):551-61.

34. Solanke BL. Factors influencing contraceptive use and non-use among women of advanced reproductive age in Nigeria. Journal of Health, Population and Nutrition.36(1):1.

35 Women's autonomy, education and contraception use in Pakistan: a national study. Saleem S, Bobak M Reprod Health. 2005 Oct 21; 2():8Khan M.A., Khanum P.A. Influence of son preference on contraceptive use in Bangladesh. Asia-Pac. Popul. J. 2000;15:43-56.

36 Abu-Ghaida, D., \& Klasen, S. (2004). The costs of missing the Millennium Development Goal on gender equity. World Development, 32(7), 10751107.

37 The World Bank - Data. (2017). Education. [online] Available at: https://data. worldbank.org/topic/education [Accessed 15 Jul. 2017]. 